\title{
Elisabetta Sibilio, Leggere Modiano
}

\section{Elena Quaglia}

\section{OpenEdition}

\section{Journals}

\section{Edizione digitale}

URL: http://journals.openedition.org/studifrancesi/4482

DOI: 10.4000/studifrancesi.4482

ISSN: 2421-5856

\section{Editore}

Rosenberg \& Sellier

\section{Edizione cartacea}

Data di pubblicazione: 1 settembre 2016

Paginazione: 368

ISSN: 0039-2944

\section{Notizia bibliografica digitale}

Elena Quaglia, «Elisabetta Sibilio, Leggere Modiano », Studi Francesi [Online], 179 (LX | II) | 2016, online dal 01 septembre 2016, consultato il 18 septembre 2020. URL : http://journals.openedition.org/ studifrancesi/4482 ; DOI : https://doi.org/10.4000/studifrancesi.4482

\section{Questo documento è stato generato automaticamente il 18 settembre 2020.}

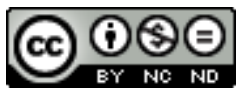

Studi Francesi è distribuita con Licenza Creative Commons Attribuzione - Non commerciale - Non opere derivate 4.0 Internazionale. 


\title{
Elisabetta Sibilio, Leggere Modiano
}

\author{
Elena Quaglia
}

\section{NOTIZIA}

ELISABETTA SIBILIO, Leggere Modiano, Roma, Carocci, 2015, «Bussole», 110 pp.

1 La monografia di Elisabetta Sibilio, pubblicata nella collana «Bussole», che raccoglie brevi saggi di orientamento e guida alla lettura, presenta al pubblico italiano il premio Nobel per la Letteratura 2014, Patrick Modiano. Per rendere più agevole la fruizione del volume, l'autrice ha tradotto in italiano tutti i testi francesi citati. I diversi capitoli non si articolano seguendo l'evoluzione cronologica dell'opera di Modiano, ma ne evidenziano piuttosto le tematiche centrali, con una grande attenzione anche alle interazioni tra letteratura e altre forme d'arte.

Dopo una breve introduzione (pp. 7-11), la monografia si apre dunque su un capitolo dedicato alla memoria e all'oblio (pp. 13-25), veri e propri elementi fondanti dell'estetica di Modiano. In questa sede trovano spazio anche le riflessioni sulla dimensione autobiografica o autofinzionale nell'opera dello scrittore e sul rapporto tra letteratura e Storia, molto sentito da un autore nato nel 1945, simbolo delle generazioni del dopo Shoah anche per le sue origini ebraiche. Il secondo capitolo (pp. 27-31) è consacrato alla "petite musique», cioè il tono uniforme che caratterizzerebbe quasi tutti i romanzi di Modiano, quasi si trattasse di un'unica opera ininterrotta, scritta in uno stile altamente riconoscibile: «Ogni nuovo romanzo è in realtà il tassello di un mosaico complesso e articolato che rappresenta la condizione umana, o meglio una condizione umana, forse quella della generazione del 1945» (p. 27).

3 I capitoli seguenti sono dedicati ai rapporti che l'opera di Modiano intrattiene con le diverse arti. Il capitolo terzo (pp. 33-44) si concentra sulla fotografia: infatti, non solo l'autore inserisce numerose fotografie nei suoi romanzi (e ne consacra uno, Chien de printemps, a un fotografo) ma ha anche scritto testi o prefazioni per delle raccolte fotografiche. Elisabetta Sibilio presta poi una certa attenzione ai testi dell'autore illustrati da Pierre Le-Tan, tra i meno noti, quali Poupée Blonde e Memory Lane. Nel 
quarto capitolo (pp. 45-61) ampio spazio è dedicato al cinema: Modiano ha scritto in effetti diverse sceneggiature, a partire dalla più celebre, quella per Lacombe Lucien di Louis Malle. Inoltre, numerosi romanzi dell'autore sono stati adattati per il cinema e Modiano stesso è stato critico cinematografico: tracce di questo suo interesse per la settima arte sono presenti in molti suoi testi letterari. Infine, l'A. fa menzione anche dell'attività di Modiano come paroliere di canzoni e come scrittore per l'infanzia.

Il quinto capitolo è incentrato sulla dimensione intertestuale dell'opera di Modiano (pp. 63-81). Nei romanzi si trovano infatti rinvii più o meno espliciti alle sue letture, che celano quasi sempre una scelta per affinità elettive, spesso legata a elementi autobiografici: è il caso per esempio dei riferimenti a Georges Perec e a Georges Simenon. Nel sesto capitolo, a degna conclusione di questo percorso di lettura dell'opera di Modiano, fatto soprattutto di spunti e suggestioni, troviamo il discorso pronunciato da Modiano di fronte all'Accademia di Svezia in occasione della cerimonia di conferimento del premio Nobel (pp. 83-93). Tale riconoscimento ha permesso che l'opera di Modiano ottenesse una maggiore visibilità internazionale: la monografia di Elisabetta Sibilio va dunque nella direzione di consolidare questa sua nuova fortuna critica. 